\title{
Cell Penetrating Peptide Conjugated Bioreducible Polymer for siRNA Delivery
}

\author{
Hye Yeong Nam ${ }^{a}$, Jaesung Kim ${ }^{a}$, Soojin Kim ${ }^{b}$, James W. Yockman ${ }^{a}$, Sung Wan Kim ${ }^{a}$, and \\ David A. BullC,* \\ a Center for Controlled Chemical Delivery (CCCD), Department of Pharmaceutics and \\ Pharmaceutical Chemistry, University of Utah, Salt Lake City, Utah 84112 \\ b Division of Hematology, School of Medicine, University of Utah, Salt Lake City, Utah 84132 \\ c Division of Cardiothoracic Surgery, School of Medicine, University of Utah, Salt Lake City, Utah \\ 84132
}

\begin{abstract}
The primary cardiomyocyte-specific peptide (PCM) and the cell-penetrating peptide (CPP), HIVTat (49-57), were incorporated into the polymer, cystamine bisacrylamide-diaminohexane (CBADAH), to increase the delivery of RNAi to target cells, specifically cardiomyocytes. Interestingly, the impact of PCM and Tat conjugation on cellular uptake and transfection efficiency was greater in $\mathrm{H} 9 \mathrm{C} 2$ rat cardiomyocytes than in NIH $3 \mathrm{~T} 3$ cells. We examined the potential for siRNA targeting SHP-1 or Fas to inhibit the apoptosis of cardiomyocytes under hypoxic conditions using PCM and Tat-modified poly(CBA-DAH), (PCM-CD-Tat). To evaluate for efficacy in inhibiting apoptosis, either Fas siRNA/polymer or SHP-1 siRNA/polymer were transfected into cardiomyocytes treated under hypoxic and serum-deprived conditions. After incubation under hypoxic conditions, treatment with either the SHP-1siRNA complex or the Fas siRNA complex resulted in an increase in cell viability and a reduction in LDH cytotoxicity. The cells transfected with either of the siRNA polyplexes had a lower incidence of apoptosis as demonstrated by Annexin V-FITC/PI staining. Both the SHP-1 siRNA/PCM-CD-Tat complex and the Fas siRNA/ PCM-CD-Tat complex warrant further investigation as therapeutic agents to inhibit the apoptosis of cardiomyocytes.
\end{abstract}

\section{Introduction}

Post-transcriptional gene silencing (PTGS) through RNA interference (RNAi) has been proposed as a potent biological strategy for the treatment of gene-related disease [1-3]. RNA interference is mediated by double-stranded RNA (dsRNA), 21-23 nucleotides in length, which binds to and triggers the degradation of target messenger RNA (mRNA) through RNA-induced silencing complex (RISC) in a sequence-specific manner [4, 5]. Although RNA interference is a very promising technology, there are significant barriers to its development as a clinically viable therapy including: (i) the need for high levels of siRNA to achieve efficacy; (ii) the generation of an innate immune response; (iii) the inherent

\footnotetext{
* Corresponding author: David A. Bull, Division of Cardiothoracic Surgery, School of Medicine, University of Utah Health Sciences Center, Room 3C127, 30 North 1900 East, Salt Lake City, Utah 84132, Phone: (801) 581-5811, Fax: (801) 585-3936, david.bull@hsc.utah.edu.

Publisher's Disclaimer: This is a PDF file of an unedited manuscript that has been accepted for publication. As a service to our customers we are providing this early version of the manuscript. The manuscript will undergo copyediting, typesetting, and review of the resulting proof before it is published in its final citable form. Please note that during the production process errors may be discovered which could affect the content, and all legal disclaimers that apply to the journal pertain.
} 
instability of the siRNA; and (iv) limited efficacy with systemic delivery. Delivery of siRNA with polymeric carriers such as polyethylenimine (PEI) and bioreducible disulfide polymers has been proposed as a means to overcome the inherent instability and poor and/or selective cellular uptake of siRNA. These polymeric carriers, however, still face major barriers with regard to transfection efficiency and cell-specific targeting for siRNA delivery.

In our previous studies, we have reported the development of novel cardiomyocyte-targeting bioreducible polymers for siRNA delivery to the myocardium $[1,6]$. In these studies, our primary cardiomyocyte targeting peptide (PCM) conjugated bioreducible polymer targeted siRNA delivery to cardiomyocytes with higher transfection efficiency. To further enhance the transfection efficiency of siRNA targeted to cardiomyocytes, we designed and synthesized a new bioreducible polymer conjugated with both a PCM peptide and a Tat peptide. The Tat sequence $\left(\mathrm{C}^{47}{ }^{47}\right.$ YRKKRRQRRR ${ }^{57}$ ), a cell-penetrating peptide (CPP) which facilitates the cellular uptake of HIV-1 [7-10], was introduced to the PCM-poly(CBADAH) (PCM-CD) to enhance the cellular uptake of siRNA. CPPs have been successfully employed as a non-viral approach for the delivery of genetic material [11-13]. In the present study, our newly modified bioreducible polymer was evaluated for specific binding to cardiomyocytes and enhanced cellular penetration into cardiomyocytes by using the cellular uptake profile and intracellular trafficking in $\mathrm{H} 9 \mathrm{C} 2$ cells, comparing with $\mathrm{NIH} 3 \mathrm{~T} 3$ cells.

To investigate whether our cardiomyocyte-targeted siRNA carrier improved siRNA delivery to cardiomyocytes, we used siRNA targeting SHP-1 or Fas. We have previously shown that our Fas siRNA delivery system inhibits cardiomyocyte apoptosis $[1,6]$. Along with TNF- $\alpha$ and Fas, the Src homology domain 2 (SH2) containing tyrosine phosphatase-1 (SHP-1) plays an important role in apoptosis and a negative regulatory role in the phosphorylation of Akt [14-18]. Akt activation is a pro-survival signal which inhibits cardiomyocyte apoptosis through extracellular signal-regulated kinase (ERK)-1/2 [19]. Therefore, silencing of SHP-1 or Fas expression with siRNA delivery should reduce apoptosis under in vitro or in vivo conditions of ischemia. In the present study, we evaluated the potential of siRNA targeting SHP-1or Fas to inhibit the apoptosis of cardiomyocytes under hypoxic and serum-deprived conditions in vitro, using our newly synthesized PCM-CD-Tat for siRNA delivery to the myocardium. Gene silencing and inhibition of apoptosis under hypoxic conditions were examined by FACS analysis and real-time RT-PCR. The innate immune response to the siRNA was measured by the interferon- $\alpha$ response in peripheral blood mononuclear cells (PBMCs).

\section{Materials and Methods}

\subsection{Materials}

$N, N^{\prime}$-Cystaminebisacrylamide (CBA) was purchased from PolySciences, Inc. (Warrington, PA). tert-Butyl- $N$-(6-aminohexyl) carbamate ( $N$-Boc-1,6-diaminohexane, $N$-Boc-DAH), trifluoroacetic acid (TFA), triisobutylsilane (TIS), N,N-diisopropylethylamine (DIPEA) and 3-[4,5-dimethylthiazol-2-yl]-2,5-diphenyltetrazolium bromide (MTT) were purchased from Sigma-Aldrich (St. Louis, MO). Fetal bovine serum (FBS), Dulbecco's phosphate buffered saline (DPBS), Roswell Park Memorial Institute 1640 medium (RPMI 1640), and Dulbecco's modified Eagle's medium (DMEM) were supplied from Invitrogen (Carlsbad, CA).

SiRNA-Fas siRNA and GFP siRNA were synthesized and supplied by Dharmacon (Lafayette, CO) and predesigned SHP-1 siRNA was obtained by Ambion (Austin, TX, USA). The siRNA sequences used in this study were the following: rat Fas siRNA, (sense) 5'-ACACGGACAGGAAACACTA-3', (anti-sense) 5'-UAGUGUUUCCUGUCCGUGU-3' and green fluorescent protein (GFP) siRNA, (sense) 5'-GCACGACTTCTTCAAGTCC-3', 
(anti-sense) 5'-GGACUUGAAGUCGUGC-3'. The sequences of predesigned rat SHP-1 siRNA candidates are shown in Fig. 1. For the cellular uptake study and intracellular trafficking assay, the anti-sense strand of the siRNA was labeled with Cy3 dye at the 3'terminal end.

\subsection{Synthesis of the PCM- poly(CBA-DAH)-Tat}

Poly(CBA-DAH), CD was synthesized according to procedures published previous by our group [20-23]. Then, conjugation of the Tat and PCM peptides to poly (CBA-DAH) was performed using hetero-bifunctional cross linker NHS-PEG 2 -Maleimide, SM(PEG) $)_{2}$ (Pierce, Rockford, IL). Poly(CBA-DAH) was activated with 5 molar equivalents of SM $(\mathrm{PEG})_{2}$ per $10 \mathrm{DAH}$ groups in anhydrous DMF for $4 \mathrm{~h}$ at room temperature and purified with a desalting column. Cysteine-terminated PCM (2 eq.) was added to the activated polymer and the reaction mixture was stirred for $24 \mathrm{~h}$ at room temperature. Tat-SH ( 2 eq.) was added and the reaction was allowed to continue an additional $24 \mathrm{~h}$. The crude mixture was purified by extensive dialysis against ultra pure water. For the synthesis of Tatpoly(CBA-DAH) and PCM- poly(CBA-DAH), 2 molar equivalents of SM (PEG) 2 per 10 DAH groups and PCM-SH (2 eq.) and Tat-SH (2 eq.) were used. The conjugation of PCM and Tat peptides was confirmed by ${ }^{1} \mathrm{H}$ NMR $\left(400 \mathrm{MHz}, \mathrm{D}_{2} \mathrm{O}\right)$.

\subsection{Polyplex formation and characterization}

The pCMV-Luci plasmid was condensed with the polymers in HEPES Buffered Saline (HBS, $10 \mathrm{mM}$ HEPES, $1 \mathrm{mM} \mathrm{NaCl}$, pH 7.4) at various weight ratios and incubated at room temperature for $30 \mathrm{~min}$. Modified polymers were combined with unmodified CD polymers (1:1) to produce complex formation for further experiments. Each polyplex was loaded onto an agarose gel $(1.0 \%, \mathrm{w} / \mathrm{v})$ containing a SYBR gel staining solution and was electrophoresed at $100 \mathrm{~V}$ for $30 \mathrm{~min}$ in TAE (10 mM Tris/HCl, $1 \%$ (v/v) acetic acid, $1 \mathrm{mM}$ EDTA) buffer. The retardation band of the polyplexes was imaged with a UV illuminator using a Gel Documentation System (Bio-Rad, Hercules, CA). The average sizes and Zeta-potential measurements of polyplexes were examined using Nano ZS (ZEN3600, Malvern Instruments) with a He-Ne ion laser $(633 \mathrm{~nm}) .0 .06 \mathrm{~mL}$ of polyplex solutions $(0.5 \mu \mathrm{g}$ of pDNA) were prepared in Hepes buffered saline (10 mM Hepes, $1 \mathrm{mM} \mathrm{NaCl}, \mathrm{pH} 7.4)$ at various weight ratios ranging from 1 to 40 . After $30 \mathrm{~min}$ incubation, polyplex solutions were diluted to final volume of $0.6 \mathrm{~mL}$ before measurement. The results were obtained as the hydrodynamic diameters and polydispersity index for size and mean values \pm SEM for zetapotential.

\subsection{Cell culture and transfection}

NIH 3 T3 and H9C2 cells from rat heart (ATCC, Manassas, VA) were cultured in DMEM medium supplemented with $10 \% \mathrm{FBS}$ at $37^{\circ} \mathrm{C}$ in a humidified incubator with $5 \% \mathrm{CO}_{2}$. $\mathrm{H} 9 \mathrm{C} 2$ cells at passage from six to ten and NIH $3 \mathrm{~T} 3$ cells were seeded in 24-well plates at a density of $5.0 \times 10^{4}$ cells/well for transfection assay and in 6-well plates at a density of $2.0 \times$ $10^{5}$ cells per well for cellular uptake and real-time RT-PCR analysis and incubated for designated period. After medium replacement with serum-free DMEM, cells were transfected with polyplexes complexed with polymers for $30 \mathrm{~min}$. After $4 \mathrm{~h}$, the medium was replaced with fresh $10 \%$ serum containing DMEM, and cells were further incubated for designated hours.

To select the SHP-1 siRNA target sequence, three SHP-1 siRNAs were complexed with PCM-CD-Tat. For hypoxic conditions, the serum deprived medium containing $1 \mathrm{mM}$ hypoxia-mimic cobalt chloride $\left(\mathrm{CoCl}_{2}\right)$ was added to the transfected cells, and the cells were further incubated for $18 \mathrm{~h}$. For the luciferase assay, transfected cells for $24 \mathrm{~h}$ were washed with DPBS and treated with $200 \mu \mathrm{L}$ of lysis buffer, followed by shaking for $30 \mathrm{~min}$ at room 
temerature. The luciferase activity of $25 \mu \mathrm{L}$ cell lysate was detected by using $100 \mu \mathrm{L}$ of luciferase assay reagent on a luminometer (Dynex Technologies Inc., Chantilly, CA). All experiments were performed in triplicate.

\subsection{Cell viability}

NIH 3T3 and H9C2 cells were seeded in 24-well plates for MTT and 96-well plates for LDH assays. Cell death and apoptosis were induced by exposing the cells to the hypoxic condition of the serum deprived medium containing $1 \mathrm{mM}$ of the hypoxia-mimic cobalt chloride $\left(\mathrm{CoCl}_{2}\right)$. After $24 \mathrm{~h}$ of transfection with polyplexes in $10 \%$ serum DMEM, the cells were further incubated under the hypoxic condition for $18 \mathrm{~h}$. For MTT assay, the cells were washed with DPBS, followed by the addition of $25 \mu \mathrm{L}$ stock solution of MTT $(2 \mathrm{mg} / \mathrm{ml}$ in PBS) to each well. After incubation at $37^{\circ} \mathrm{C}$ for $4 \mathrm{~h}$, the medium was removed and $150 \mu \mathrm{L}$ DMSO was added to dissolve the formazan crystal. The absorbance was measured using a microplate reader (Model 680, Bio-Rad Lab, Hercules, CA) at $570 \mathrm{~nm}$, and cell viability was recorded as a percentage relative to control cells in quadruplicate. An LDH assay kit was used to detect the LDH activity in a $100 \mu \mathrm{L}$ aliquot of culture medium (Clontech) according to the vendor's instructions. Maximum LDH activity was measured by lysing the cells with $1 \%$ Triton X-100. The released LDH activity in culture medium was calculated as a percentage relative to the total cellular LDH activity.

\subsection{Real-time RT-PCR}

Total RNA was obtained from the transfected cells using TRIzol ${ }^{\circledR}$ Reagent (Invitrogen, Carlsbad, CA). One $\mu \mathrm{g}$ pure RNA was reverse transcribed with SuperScript ${ }^{\mathrm{TM}}$ III (Invitrogen, Carlsbad, CA), and real-time PCR using Taq-Man Gene Expression Assays ${ }^{\circledR}$ (Applied Biosystems, Foster City, CA, USA) was performed using a 7500 Fast Real-Time PCR System (Applied Biosystems, Foster City, CA, USA). All reactions were carried out in a $20 \mu \mathrm{l}$ reaction volume in duplicate according to the manufacturer's instructions. The PCR amplification reaction was performed at $50^{\circ} \mathrm{C}$ for $2 \mathrm{~min}$ and at $95^{\circ} \mathrm{C}$ for $10 \mathrm{~min}$, followed by 40 cycles of $95^{\circ} \mathrm{C}$ for $15 \mathrm{~s}$ and at $60^{\circ} \mathrm{C}$ for $1 \mathrm{~min}$. Relative amounts of Fas and SHP-1 mRNA in $\mathrm{H} 9 \mathrm{C} 2$ cells were normalized to GAPDH mRNA.

\subsection{FACS analysis and confocal microscopy}

To investigate cellular uptake, cells were transfected with the polyplex of pDNA labeled with YOYO-1 iodide. The cells were treated with polyplex solutions for $4 \mathrm{~h}$ at $37^{\circ} \mathrm{C}$, washed with cold DPBS and then trypsinized. The collected cells were suspended in $1 \mathrm{~mL}$ DPBS. The cellular uptake was examined with a FACScan analyzer (Becton Dickinson, San Jose, CA) using Cell Quest software. A total of 10,000 cells were acquired for each analysis.

For confocal microscopy, H9C2 cells were seeded on confocal imaging dishes (Glass Bottom microwells, MatTek Corp., Ashland, MA) at a density of $5.0 \times 10^{4}$ cells/well. The polyplexes with $1 \mu \mathrm{g}$ of YOYO-1 iodide-labeled pDNA were prepared and transfected into cells in a serum-free DMEM. After $1 \mathrm{~h}$ of incubation, treated cells were further incubated with $10 \%$ DMEM media for $1 \mathrm{~h}$ at $37^{\circ} \mathrm{C}$. The intracellular trafficking of YOYO-1 iodidelabeled pDNA within the cells was visualized by a confocal laser scanning microscope (FV1000-XY Confocal Olympus IX81 microscope, Melville, NY).

\subsection{Apoptosis assay}

After the desired period of transfection and exposure to the hypoxic condition, cells were washed, trypsinized and centrifuged. The collected cells were resuspended in $500 \mu \mathrm{L}$ of Annexin V Binding buffer provided with the Annexin V FITC kit (MBL, Woburn, MA), and $5 \mu \mathrm{L}$ of Annexin V-FITC and $5 \mu \mathrm{L}$ of PI were added. Next, the cells were incubated at $4{ }^{\circ} \mathrm{C}$ 
for $30 \mathrm{~min}$ in the dark. Samples were then analyzed with a BD FACScan analyzer (Becton Dickinson). To observe the cells, the stained cell suspension was placed on a glass slide and examined via fluorescence microscopy.

\subsection{Interferon-alpha ELISA assay}

Peripheral blood mononuclear cells (PBMCs) were supplied by SeraCare Life Sciences Inc. (Gaithersburg, MD). Freshly thawed cells were seeded in 96-well plates and cultured in RPMI 1640 medium with 10\% FBS. The cells were treated with various siRNA formulations to at a final siRNA concentration of $3 \mu \mathrm{g} / \mathrm{mL}$, and synthetic Poly(I:C) (SigmaAldrich) was used to induce an immune response in PBMCs as a positive control. After $24 \mathrm{~h}$ of incubation, the culture supernatants were collected and assayed for INF- $\alpha$ by sandwich ELISA (Invitrogen) according to the supplier's instructions.

\section{Results and Discussion}

\subsection{Synthesis and characterization of PCM-poly(CBA-DAH)-Tat}

Cell penetrating peptides (CPP)s, such as the Tat peptide, have been used extensively in vitro and in vivo to facilitate the uptake of a range of biological chemicals. For enhanced penetration with targeting, the Tat peptide was introduced to the cardiomyocyte-targeting PCM-modified polymer. Cysteine-terminated PCM and Tat peptide were added to the $\mathrm{SM}(\mathrm{PEG})_{2}$ activated poly(CBA-DAH) (Fig 1A). The conjugation was confirmed by the NMR peaks of tryptophan (specifically, the peaks around 7.6-7.0 ppm in the aromatic protons of tryptophan) in PCM and tyrosine (7.0-6.4 ppm of the aromatic tyrosine) in Tat. Tat or PCM peptide conjugated CD were also synthesized as controls. Polyplex formation of these polymers and anionic genes was determined using agarose gel electrophoresis. For complex formation and use in further experiments, the polymers were combined with unmodified CD polymers in a 1:1 ratio owing to steric hindrance of the conjugated peptides and the loss of positive charge. Gel retardation results demonstrated that peptide-modified polymers could effectively condense anionic genes at a weight ratio over 5 (Fig 1B). As shown in Table 1, the polyplex sizes were less than $200 \mathrm{~nm}$ at a weight ratio of over 10:1 and the zeta potential increased according to the increase of polyplex weight ratio, finally reaching the positive plateau values $(20-25 \mathrm{mV})$. From the particle size and the surface charges, it is supposed that these newly peptide modified bioreducible polymers can efficiently complex with polyanionic genes into appropriate sizes for effective gene delivery.

\subsection{Cellular uptake and intracellular trafficking of polyplexes}

In order to investigate enhanced transfection efficiency via Tat conjugation, in vitro transfection and cellular uptake assays were performed in NIH 3T3 and $\mathrm{H} 9 \mathrm{C} 2$ cells. While PCM conjugation showed better transfection efficiency in H9C2 than in NIH 3T3 cells, Tatmodification showed a similar enhanced level of efficiency in both cell lines. Given the combined and synergic effect of the PCM and Tat peptides, the transfection assay of poly(CBA-DAH) conjugated with both PCM and Tat, PCM-CD-Tat, in H9C2 cells demonstrated a marked enhancement of transfection efficiency compared to conjugation with either PCM or Tat modification alone (Fig 2A). This enhanced cellular penetration with both Tat and PCM conjugation was also exhibited in the cellular uptake by FACS analysis (Fig 3A). As expected, the cellular uptake of theTat-CD polyplex was similar in both cells (158\% in NIH 3T3 cells and $161 \%$ in $\mathrm{H} 9 \mathrm{C} 2$ cells) compared to unmodified CD polyplex ( $100 \%$ as controls). However, when the PCM-CD-Tat polyplex was added to H9C2 and NIH $3 \mathrm{~T} 3$ cells, the cellular uptake in $\mathrm{H} 9 \mathrm{C} 2$ cardiomyocytes was higher than in NIH 3T3 cells ( $171 \%$ and $149 \%$, respectively). To confirm the penetrating ability of Tat peptide modification, the intracellular trafficking of polyplexes was observed by confocal 
microscopy in H9C2 cells. As shown in Fig 3B, the cells treated with PCM-CD-Tat polyplexes, whose pDNA was labeled with YOYO-1 iodide, showed a more intense green signal in the cytoplasm with an additional $2 \mathrm{~h}$ of treatment. These results demonstrate that conjugation with the Tat peptide increases transfection efficiency, while addition of the PCM peptide results in a further increase in transfection efficiency in $\mathrm{H} 9 \mathrm{C} 2$ cardiomyocytes. In addition, in vitro cytotoxicity by MTT assay demonstrated good cell viability after transfection using the PCM-CD-Tat polyplexes (Fig 2B). These results verify that PCM conjugation facilitates cardiomyocyte-targeting, while Tat peptide conjugation facilitates gene delivery into the cells without significant cytotoxicity.

\subsection{Selection of the SHP-1 siRNA sequence}

The extent of cardiomyocyte apoptosis contributes significantly to the ultimate size and clinical impact of an acute myocardial infarction (AMI) [24-26]. In many types of cells, apoptosis can be induced by activation of death domain-containing receptors, particularly by binding of TNF- $\alpha$ and Fas to the TNF- $\alpha$ receptor-1 (TNFR-1) and the Fas receptor (FAS-R), respectively, in cardiomyocytes. Fas is known as a critical mediator of AMI following ischemia-reperfusion injury [14]. Several recent reports have shown that Fas gene silencing with siRNA is effective in limiting hypoxia-induced apoptosis [11,27]. We have investigated and published on the anti-apoptotic effect of Fas siRNA using a polymeric gene delivery system[1, 6]. Src homology domain 2 (SH2)-containing tyrosine phosphatase-1 (SHP-1) has also been reported as a key molecule in the apoptotic pathway of many cells. SHP-1 binding to death receptors such as TNFR-1 and FAS-R promotes apoptosis through a regulatory role in de-phosphorylation in signal transduction pathways [27-29]. The inhibition of the SHP-1 gene with siRNA may result in a decrease in cardiomyocyte apoptosis and an increase in cardio-protection by Akt activation [30]. In this study, we investigated the ability of synthetic siRNA to SHP-1 or Fas siRNA to inhibit apoptosis under hypoxic and serum-deprived conditions. The selection of siRNA sequences for the SHP-1 gene targeting was carried out using RNAi-mediated gene knock-down, and we had previously developed a sequence for Fas siRNA. Suppression of the expression of SHP-1 gene using PCM-CD-Tat polymeric carrier was examined in $\mathrm{H} 9 \mathrm{C} 2$ using real-time RT-PCR. SHP-1 siRNA and, of the three synthesized siRNAs (Fig 4A), no. 2 showed the most potent inhibition of the SHP-1 in H9C2 cells (Fig 4B). The quantitative RT-PCR results showed that siRNA no. 2 inhibited Fas mRNA production by $61 \%(50 \mathrm{nM})$ and $70 \%(100 \mathrm{nM})$ compared to the untreated control. Based on these results, SHP-1 siRNA no. 2 was selected as the most potent siRNA molecule for SHP-1 and used for further studies along with our previously described siRNA to Fas [1,6].

\subsection{Cell death following treatment with the anti-apoptotic siRNA/polymer complex}

LDH and MTT assays were performed to quantify the extent of cell death in order to determine the anti-apoptotic effect of the Fas or SHP-1 siRNA/PCM-CD-Tat polyplex (siRNA: $50 \mathrm{nM}$, weight ratio: 20). After incubation under hypoxic and serum-deprived conditions, the relative cell viability of untreated or GFP siRNA complex treated H9C2 cells was decreased to only $33 \%$. Cell viability was increased following treatment with SHP-1 siRNA to $56 \%$ and following treatment with Fas siRNA to $49 \%$. LDH-cytotoxicity was reduced to $60 \%$ with SHP-1 siRNA and was reduced to $75 \%$ with Fas siRNA (Fig 5). Following these results, the SHP-1 and Fas siRNA delivery systems were investigated further to determine their efficacy in inhibiting apoptosis.

\subsection{Cardiomyocyte-targeted gene silencing and anti-apoptotic activity}

siRNAs to either SHP-1 or Fas were added to the cardiomyocyte-targeting and enhanced cell-penetrating PCM-poly(CBA-DAH)-Tat conjugated polymer and evaluated for their efficacy to inhibit cardiomyocyte apoptosis. The gene silencing and anti-apoptotic activity 
of the siRNAs were investigated using the PCM and Tat peptide modified polymer under hypoxic and serum-deprived conditions. Levels of SHP-1 and Fas mRNA under hypoxic conditions were decreased in $\mathrm{H} 9 \mathrm{C} 2$ cells following treatment with the siRNA polyplex systems. Using real-time RT-PCR, the polypex with both PCM and Tat $\left(\mathrm{PCM}^{+} / \mathrm{Tat}^{+}\right)$ showed more effective suppression of SHP-1and Fas in H9C2 cells than did the other polyplexes (Fig 6). This result validates the cell-penetrating efficacy of the Tat peptide conjugation.

Annexin V-FITC/PI staining was used to determine the extent of cardiomyocyte apoptosis. Significant silencing of the target SHP-1and Fas genes led to a decrease in the apoptosis of cardiomyocytes under hypoxic and serum-deprived conditions. As shown in Fig 7A, normal cardiomyocytes displayed a low percentage of apoptosis (FITC positive, $0.53 \%$ ), while the apoptotic rate was increased to $93 \%$ under hypoxic conditions with $\mathrm{CoCl}_{2}$ treatment. Treatment with the SHP-1 polyplex system decreased the population of Annexin V-FITC positive cells to $41 \%$, while treatment with the Fas polyplex system decreased the population of Annexin V-FITC positive cells to 50\% (Fig 7B). These results demonstrate that the cardiomyocyte-targeting and enhanced cell-penetrating PCM-poly(CBA-DAH)-Tat conjugated polymer can be a potent carrier for SHP-1or Fas siRNA into cardiomyocytes and inhibit apoptosis in $\mathrm{H} 9 \mathrm{C} 2$ cells.

\subsection{Immune response of siRNA/PCM-poly(CBA-DAH)-Tat polyplex}

Several studies have suggested inherent toxicity from the immune stimulation of certain duplex siRNAs, including an siRNA-induced interferon response $[4,31]$. Therefore, prior to in vivo application, the immunogenicity of any new siRNA delivery system needs to be determined. We have previously reported that the Fas siRNA polyplex does not elicit a detectable immune response [1]. In order to examine the immune response of our new synthetic SHP-1 siRNA, the induction of interferon-alpha (IFN- $\alpha$ ) in response to the siRNA polyplex systems was investigated in peripheral blood mononuclear cells (PBMCs). The potential immune-stimulant, synthetic double poly(I:C) [32], was used as a control to induce IFN- $\alpha$. Poly(I:C) strongly induced IFN- $\alpha$ in PBMCs with the polyplex system, but there was no detectable IFN- $\alpha$ stimulation in response to the SHP-1 siRNA polyplex system. Based on these results, the Fas and SHP-1 siRNA polyplex cardiomyocyte-targeting delivery systems do not appear to generate an immune response.

\section{Conclusion}

In this study, we described the development of a cardiomyocyte-targeting non-viral gene carrier and anti-apoptotic candidate siRNAs to inhibit cardiomyocyte apoptosis. Our newly synthesized PCM-poly(CBA-DAH)-Tat was evaluated to study the efficacy of combining a cardiomyocyte-targeting PCM peptide and a cell penetrating Tat peptide. Incorporation of the PCM and Tat peptides into a bioreducible poly(CBA-DAH) polymer enhanced the transfection efficiency of the cardiomyocyte-targeting delivery system. Through suppression of SHP-1 or Fas, transfection with the SHP-1 or the Fas siRNA polyplex significantly decreased cardiomyocyte apoptosis. Based on these results, we propose that the SHP-1 and Fas siRNA/PCM-poly(CBA-DAH)-Tat polyplexes are potent cardiomyocyte-targeted siRNA delivery systems for the treatment of cardiovascular disease.

\section{Acknowledgments}

This work was financially supported by NIH grants HL HL071541 (DAB) and 065447 (SWK). 


\section{References}

1. Kim SH, Jeong JH, Ou M, Yockman JW, Kim SW, Bull DA. Cardiomyocyte-targeted siRNA delivery by prostaglandin $\mathrm{E}(2)$-Fas siRNA polyplexes formulated with reducible poly(amido amine) for preventing cardiomyocyte apoptosis. Biomaterials. 2008; 29:4439-4446. [PubMed: 18725170]

2. Hammond SM, Caudy AA, Hannon GJ. Post-transcriptional gene silencing by double-stranded RNA. Nat Rev Genet. 2001; 2:110-119. [PubMed: 11253050]

3. McManus MT, Sharp PA. Gene silencing in mammals by small interfering RNAs. Nat Rev Genet. 2002; 3:737-747. [PubMed: 12360232]

4. Aigner A. Gene silencing through RNA interference (RNAi) in vivo: strategies based on the direct application of siRNAs. J Biotechnol. 2006; 124:12-25. [PubMed: 16413079]

5. Hammond SM, Bernstein E, Beach D, Hannon GJ. An RNA-directed nuclease mediates posttranscriptional gene silencing in Drosophila cells. Nature. 2000; 404:293-296. [PubMed: 10749213]

6. Nam HY, McGinn A, Kim PH, Kim SW, Bull DA. Primary cardiomyocyte-targeted bioreducible polymer for efficient gene delivery to the myocardium. Biomaterials. 2010; 31:8081-8087. [PubMed: 20674007]

7. Ko YT, Hartner WC, Kale A, Torchilin VP. Gene delivery into ischemic myocardium by doubletargeted lipoplexes with anti-myosin antibody and TAT peptide. Gene Ther. 2008; 16:52-59. [PubMed: 18701915]

8. Torchilin VP, Levchenko TS, Rammohan R, Volodina N, Papahadjopoulos-Sternberg B, D'Souza GG. Cell transfection in vitro and in vivo with nontoxic TAT peptide-liposome-DNA complexes. Proc Natl Acad Sci U S A. 2003; 100:1972-1977. [PubMed: 12571356]

9. Tunnemann G, Karczewski P, Haase H, Cardoso MC, Morano I. Modulation of muscle contraction by a cell-permeable peptide. J Mol Med. 2007; 85:1405-1412. [PubMed: 17717642]

10. Wei B, Wei Y, Zhang K, Wang J, Xu R, Zhan S, et al. Development of an antisense RNA delivery system using conjugates of the MS2 bacteriophage capsids and HIV-1 TAT cell penetrating peptide. Biomed Pharmacother. 2009; 63:313-318. [PubMed: 18823738]

11. Endoh T, Ohtsuki T. Cellular siRNA delivery using cell-penetrating peptides modified for endosomal escape. Adv Drug Deliv Rev. 2009; 61:704-709. [PubMed: 19383521]

12. Lundberg P, Langel Ü. A brief introduction to cell-penetrating peptides. J Mol Recognit. 2003; 16:227-233. [PubMed: 14523933]

13. Meade BR, Dowdy SF. Exogenous siRNA delivery using peptide transduction domains/cell penetrating peptides. Adv Drug Deliv Rev. 2007; 59:134-140. [PubMed: 17451840]

14. Bryant D, Becker L, Richardson J, Shelton J, Franco F, Peshock R, et al. Cardiac failure in transgenic mice with myocardial expression of tumor necrosis factor-alpha. Circulation. 1998; 97:1375-1381. [PubMed: 9577949]

15. Song W, Lu X, Feng Q. Tumor necrosis factor-alpha induces apoptosis via inducible nitric oxide synthase in neonatal mouse cardiomyocytes. Cardiovasc Res. 2000; 45:595-602. [PubMed: 10728381]

16. Stephanou A, Scarabelli TM, Brar BK, Nakanishi Y, Matsumura M, Knight RA, et al. Induction of apoptosis and Fas receptor/Fas ligand expression by ischemia/reperfusion in cardiac myocytes requires serine 727 of the STAT-1 transcription factor but not tyrosine 701. J Biol Chem. 2001; 276:28340-28347. [PubMed: 11309387]

17. Sugano M, Tsuchida K, Hata T, Makino N. RNA interference targeting SHP-1 attenuates myocardial infarction in rats. FASEB J. 2005; 19:2054-2056. [PubMed: 16223786]

18. Yamaoka M, Yamaguchi S, Suzuki T, Okuyama M, Nitobe J, Nakamura N, et al. Apoptosis in rat cardiac myocytes induced by Fas ligand: priming for Fas-mediated apoptosis with doxorubicin. J Mol Cell Cardiol. 2000; 32:881-889. [PubMed: 10888243]

19. Granata R, Trovato L, Gallo MP, Destefanis S, Settanni F, Scarlatti F, et al. Growth hormonereleasing hormone promotes survival of cardiac myocytes in vitro and protects against ischaemiareperfusion injury in rat heart. Cardiovasc Res. 2009; 83:303-312. [PubMed: 19293247]

20. Kim TI, Ou M, Lee M, Kim SW. Arginine-grafted bioreducible poly(disulfide amine) for gene delivery systems. Biomaterials. 2009; 30:658-664. [PubMed: 19007981] 
21. Ou M, Wang XL, Xu R, Chang CW, Bull DA, Kim SW. Novel biodegradable poly(disulfide amine)s for gene delivery with high efficiency and low cytotoxicity. Bioconjug Chem. 2008; 19:626-633. [PubMed: 18314939]

22. Brumbach JH, Lin C, Yockman J, Kim WJ, Blevins KS, Engbersen JFJ, et al. Mixtures of poly(triethylenetetramine/cystamine bisacrylamide) and poly(triethylenetetramine/cystamine bisacrylamide)-g-poly(ethylene glycol) for improved gene delivery. Bioconjug Chem. 2010; 21:1753-1761. [PubMed: 20882996]

23. Christensen LV, Chang CW, Kim WJ, Kim SW, Zhong Z, Lin C, et al. Reducible poly(amido ethylenimine)s designed for triggered intracellular gene delivery. Bioconjug Chem. 2006; 17:1233-1240. [PubMed: 16984133]

24. Kajstura J, Cheng W, Reiss K, Clark WA, Sonnenblick EH, Krajewski S, et al. Apoptotic and necrotic myocyte cell deaths are independent contributing variables of infarct size in rats. Lab Invest. 1996; 74:86-107. [PubMed: 8569201]

25. Lee P, Sata M, Lefer DJ, Factor SM, Walsh K, Kitsis RN. Fas pathway is a critical mediator of cardiac myocyte death and MI during ischemia-reperfusion in vivo. Am J Physiol Heart Circ Physiol. 2003; 284:H456-463. [PubMed: 12414449]

26. Nabel EG. Cardiovascular disease. N Engl J Med. 2003; 349:60-72. [PubMed: 12840094]

27. Chen HE, Chang S, Trub T, Neel BG. Regulation of colony-stimulating factor 1 receptor signaling by the SH2 domain-containing tyrosine phosphatase SHPTP1. Mol Cell Biol. 1996; 16:36853697. [PubMed: 8668185]

28. Daigle I, Yousefi S, Colonna M, Green DR, Simon HU. Death receptors bind SHP-1 and block cytokine-induced anti-apoptotic signaling in neutrophils. Nat Med. 2002; 8:61-67. [PubMed: 11786908]

29. Mizuno K, Tagawa Y, Mitomo K, Watanabe N, Katagiri T, Ogimoto M, et al. Src homology region 2 domain-containing phosphatase 1 positively regulates $\mathrm{B}$ cell receptor-induced apoptosis by modulating association of B cell linker protein with Nck and activation of c-Jun NH2-terminal kinase. J Immunol. 2002; 169:778-786. [PubMed: 12097380]

30. Matsui T, Tao J, del Monte F, Lee KH, Li L, Picard M, et al. Akt activation preserves cardiac function and prevents injury after transient cardiac ischemia in vivo. Circulation. 2001; 104:330335. [PubMed: 11457753]

31. Kariko K, Bhuyan P, Capodici J, Weissman D. Small interfering RNAs mediate sequenceindependent gene suppression and induce immune activation by signaling through toll-like receptor 3. J Immunol. 2004; 172:6545-6549. [PubMed: 15153468]

32. Hornung V, Guenthner-Biller M, Bourquin C, Ablasser A, Schlee M, Uematsu S, et al. Sequencespecific potent induction of IFN-alpha by short interfering RNA in plasmacytoid dendritic cells through TLR7. Nat Med. 2005; 11:263-270. [PubMed: 15723075] 
A

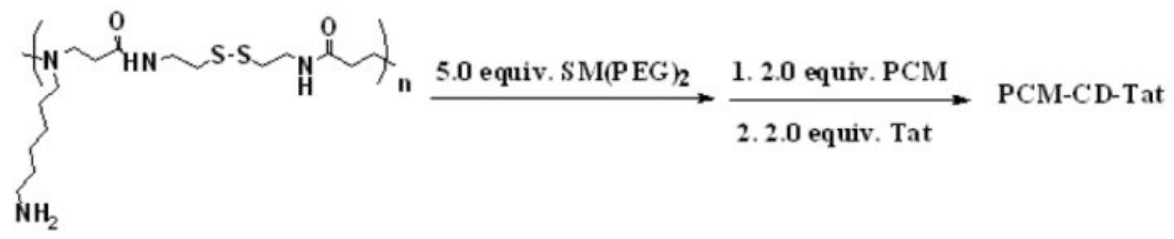

PCM peptil e: C-WLSEAGPVVTVRALRGTGSW

Tat peptide: C-YGRKKRRQRRR

B

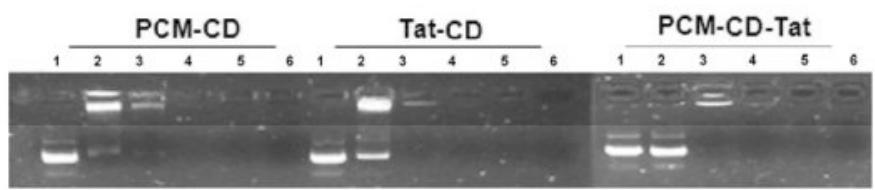

Figure 1.

(A) Schematic diagram of PCM and Tat-conjugated poly(CBA-DAH) (PCM-CD-Tat). (B) Agarose gel electrophoresis of polymers complexed with plasmid DNA at the various weight ratios of polymer/pDNA $=0,1,5,10,20$ and 40 (lanes 1, 2, 3, 4, 5 and 6, respectively). 
A
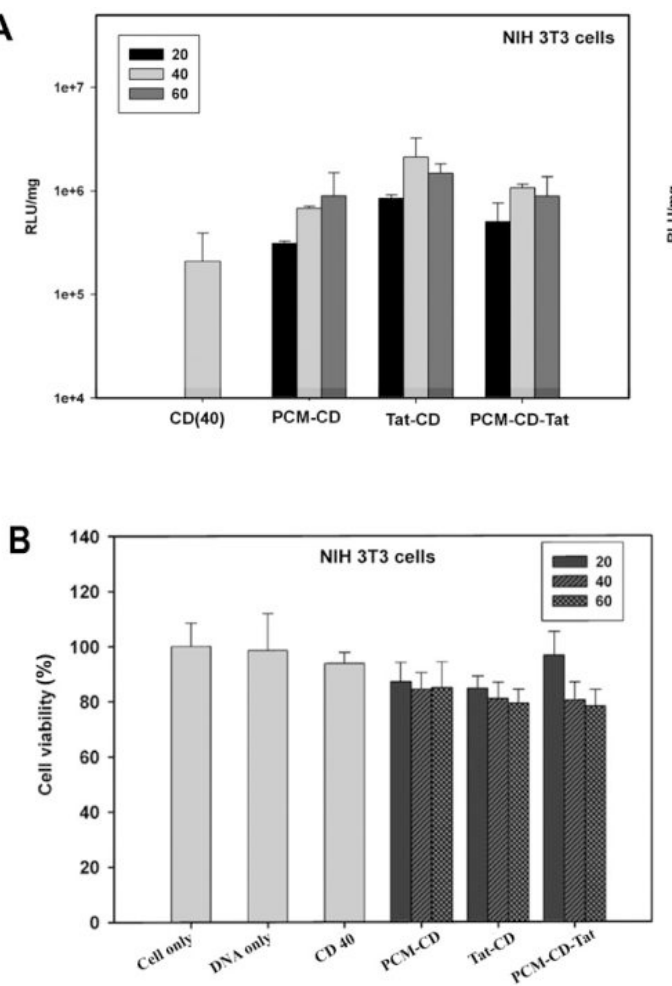
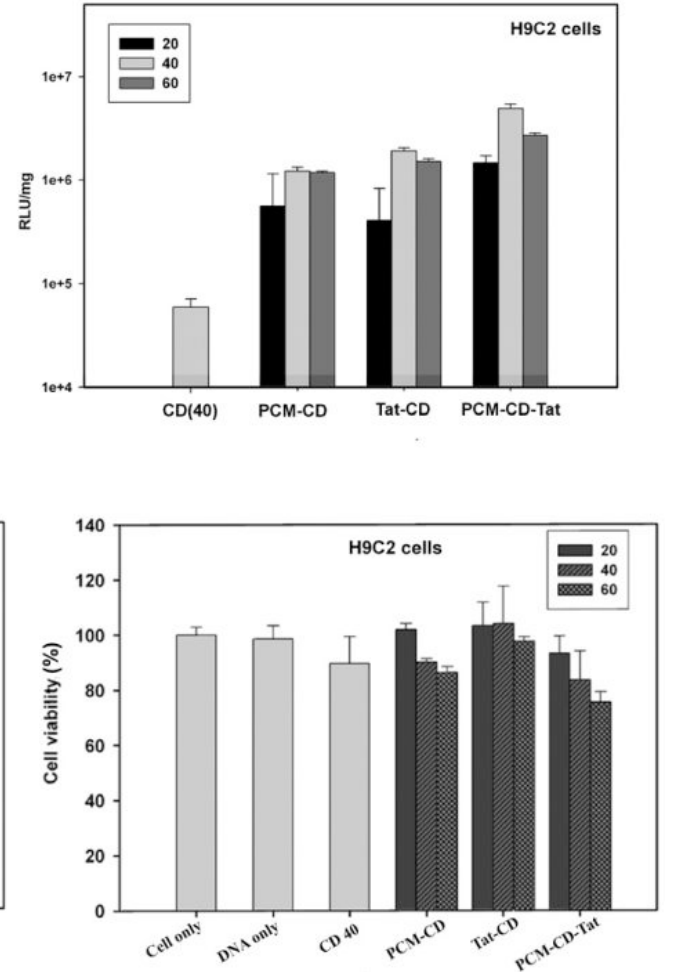

Figure 2.

(A) The transfection results of polymer/pDNA at various weight ratios and (B) Cytotoxicity assay in $\mathrm{H} 9 \mathrm{C} 2$ cells and NIH3T3 cells. 
A

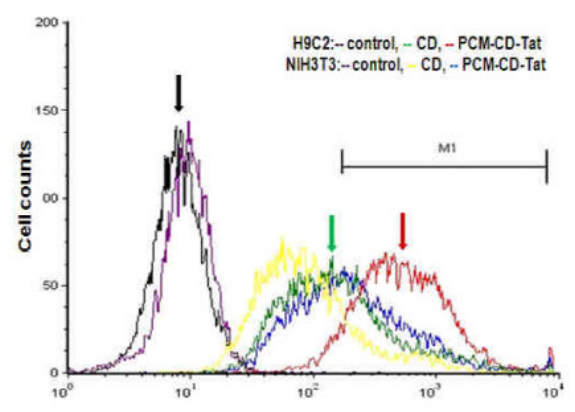

B

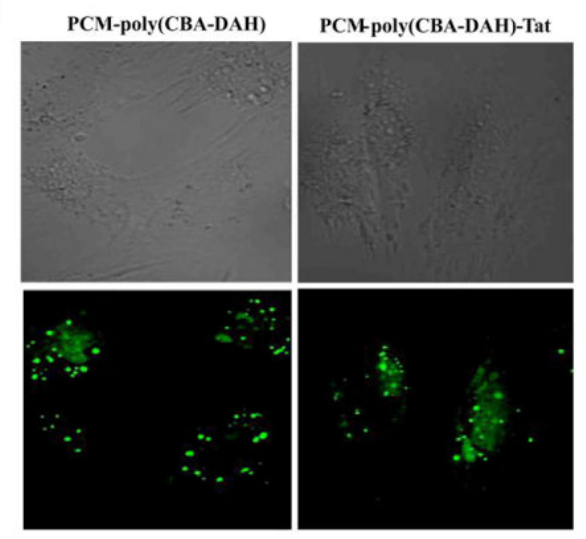

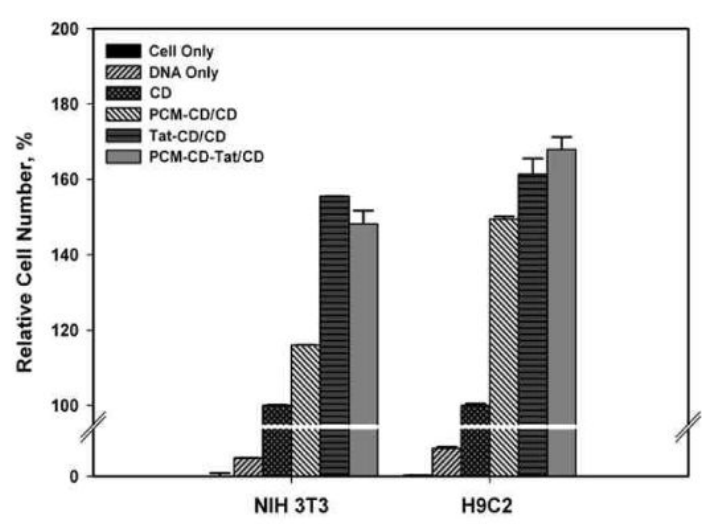

Figure 3.

Cellular uptake and intracellular trafficking of polyplexes. (A) Flow cytometry results of polyplexes at a weight ratio 40 in NIH3T3 and $\mathrm{H} 9 \mathrm{C} 2$ cells. (B) Intracellular trafficking of YOYO-1 iodide-labeled pDNA polyplex in $\mathrm{H} 9 \mathrm{C} 2$ cells incubated with PCM-conjugated or PCM and Tat-conjugated polymer using confocal microscopy after $2 \mathrm{~h}$ treatment. 
A

\begin{tabular}{|l|l|}
\hline SHP-1 siRNA no 1 & $\begin{array}{l}\text { 5'-GCACAGUACAAGUUUAUUU-3' } \\
\text { 3'-CGUGUCAUGUUCAAAUAAA-5' }\end{array}$ \\
\hline SHP-1 siRNA no 2 & $\begin{array}{l}\text { 5'-GGACAUUUCUUGUGCGUGA-3' } \\
\text { 3'-CCUGUAAAGAACACGCACU-5' }\end{array}$ \\
\hline SHP-1 siRNA no 3 & $\begin{array}{l}\text { 5'-GCAGAGUACAAACUUCGAA-3' } \\
\text { 3'-CGUCUCAUGUUUGAAGCUU-5' }\end{array}$ \\
\hline
\end{tabular}

B

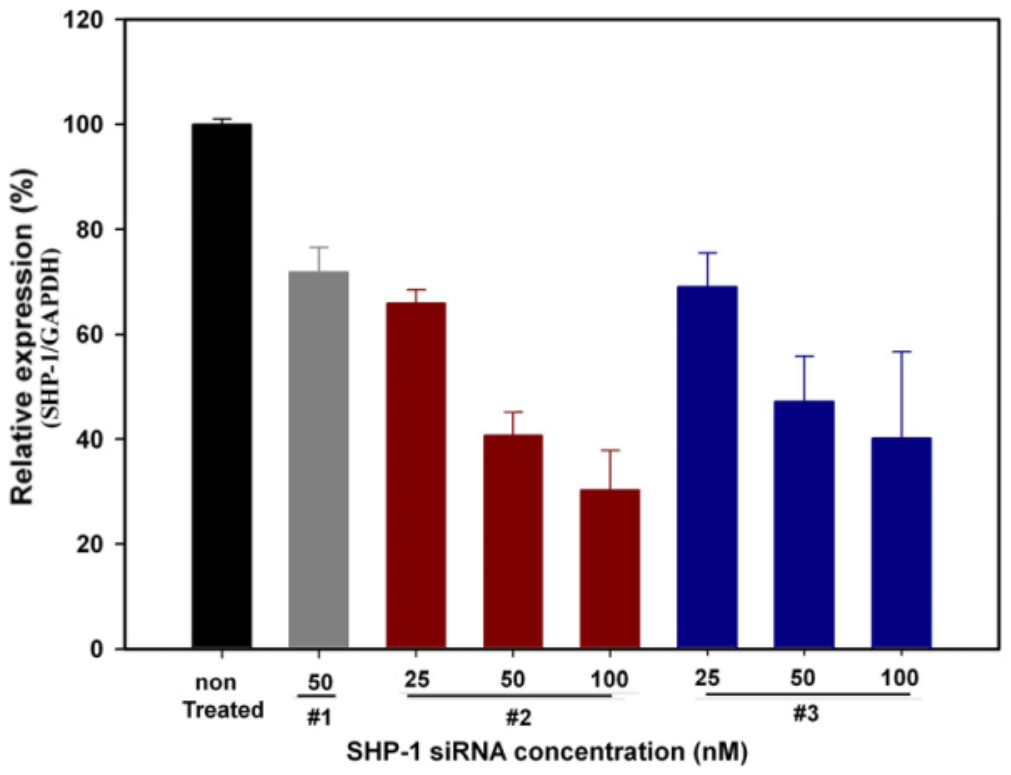

Figure 4.

Selection of the rat SHP-1 siRNA target sequence. (A) Three siRNA sequences; the upper is sense strand and the lower is antisense strand. (B) Silencing of target gene SHP-1 expression by siRNA transfection using by quantitative real-time PCR 

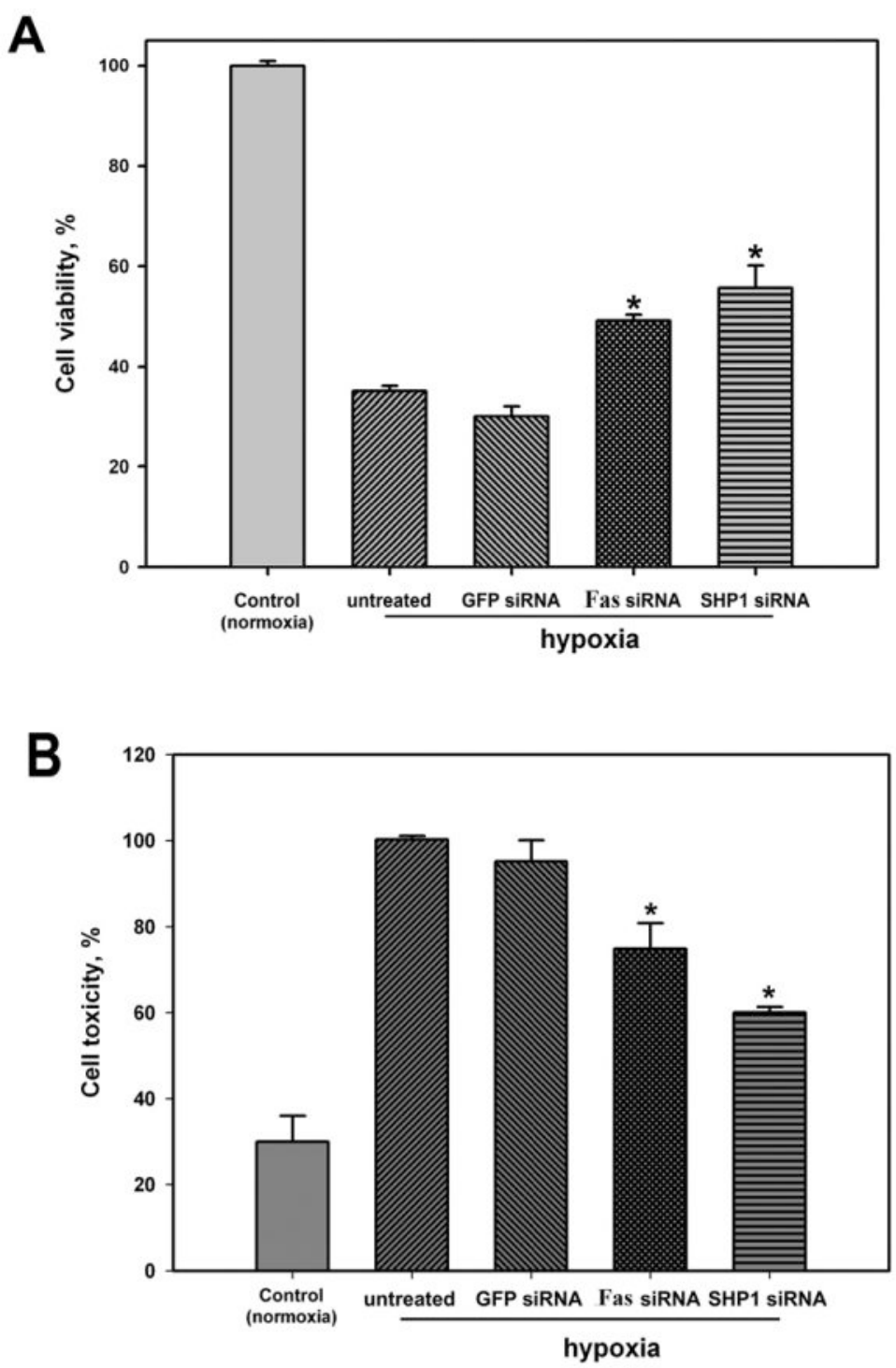

Figure 5.

Anti-apoptotic activity of SHP-1 siRNA and Fas siRNA under hypoxic and serum-deprived conditions (siRNA: $50 \mathrm{nM}$, weight ratio: 20). (A) Cell viability by MTT assay. Relative cell viability was calculated as $100 \times \mathrm{A}_{570}$ of treated cells/A $\mathrm{A}_{570}$ of control cells. (B) Cell toxicity by LDH assay. Results were normalized against untreated $\mathrm{H} 9 \mathrm{C} 2$ cells under hypoxic conditions. $50 \mathrm{nM}$ siRNA *p $<0.05$ versus untreated and GFP siRNA transfected cells under hypoxic conditions. 

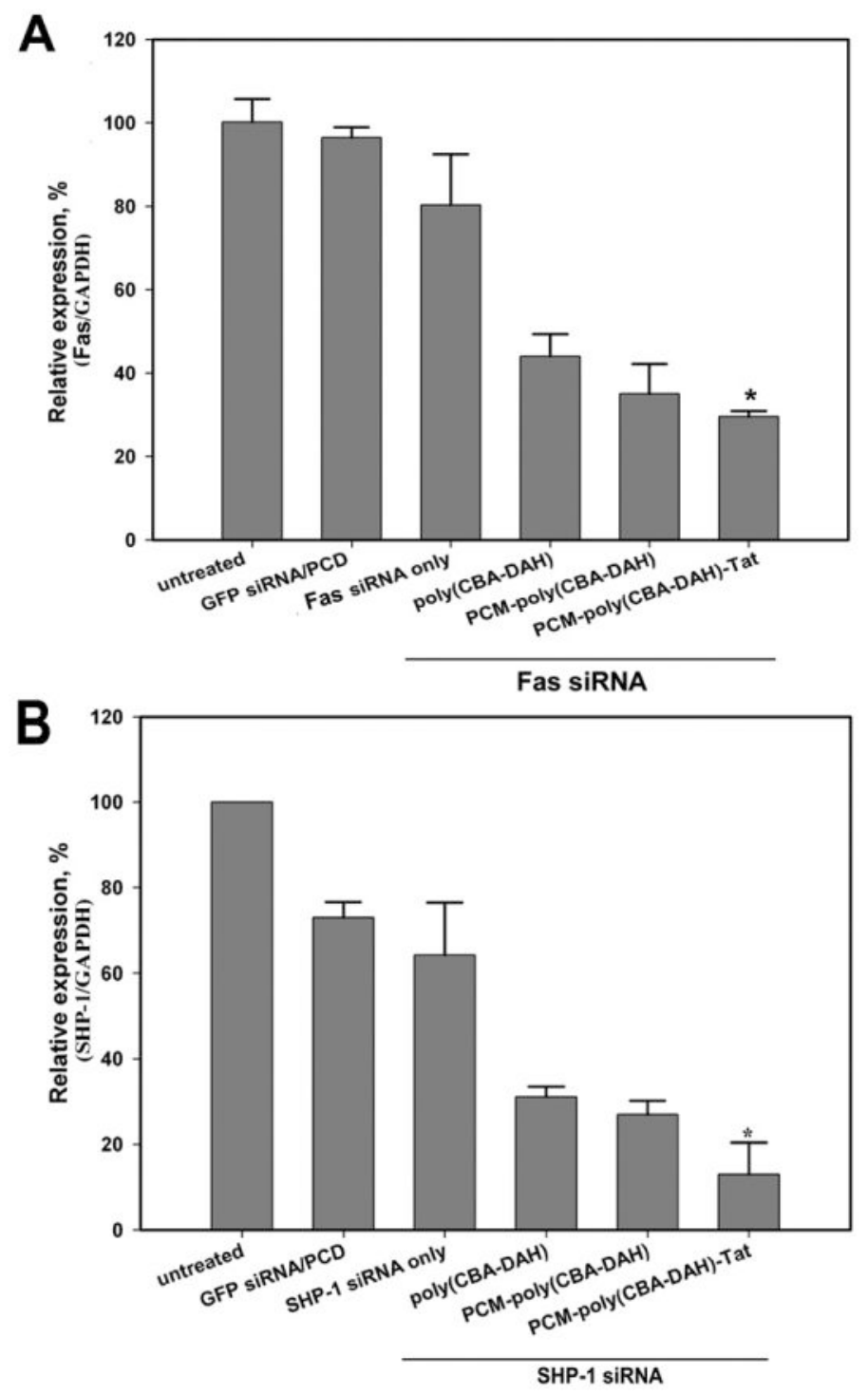

Figure 6.

Quantitative real-time PCR for (A) Fas and (B) SHP-1. The gene expression levels in Fas or SHP-1 siRNA-transfected H9C2 cells was normalized to that in untreated H9C2 cells under hypoxic conditions. GAPDH was used as a control. *p $<0.05$ for relative expression of Fas or SHP-1 versus all other groups 
A

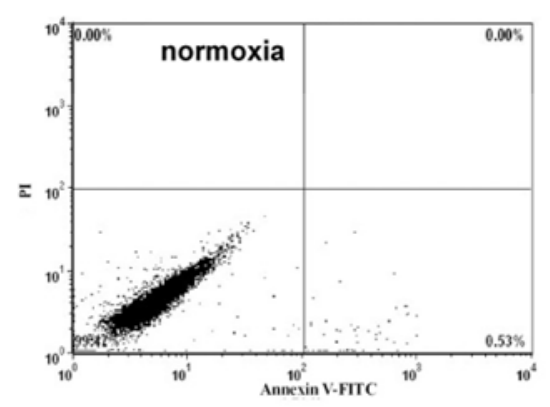

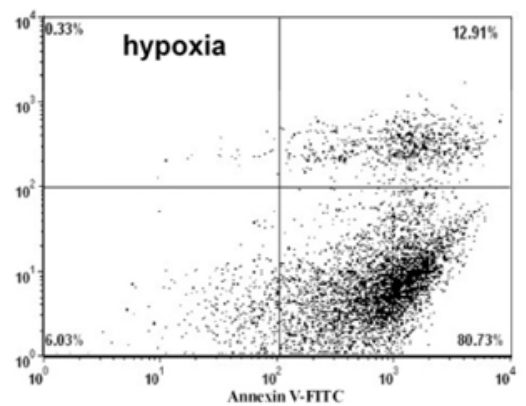

B

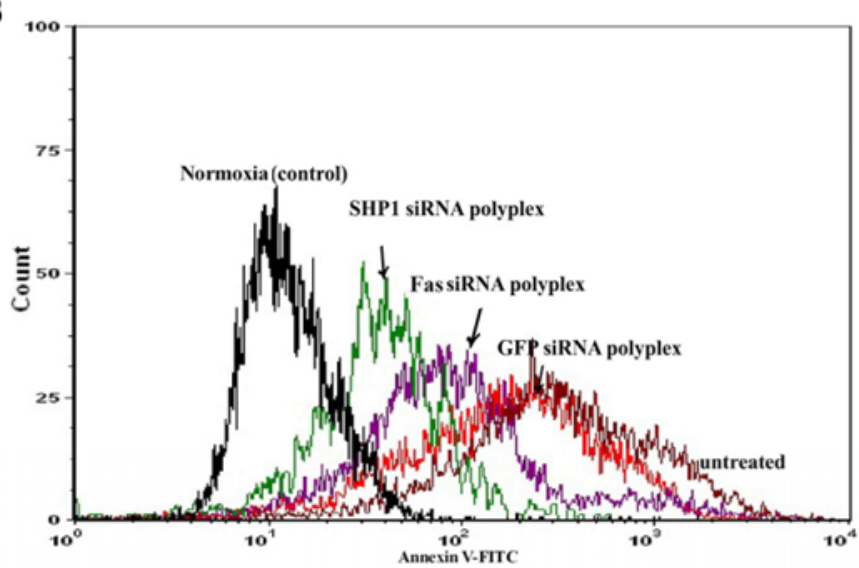

C

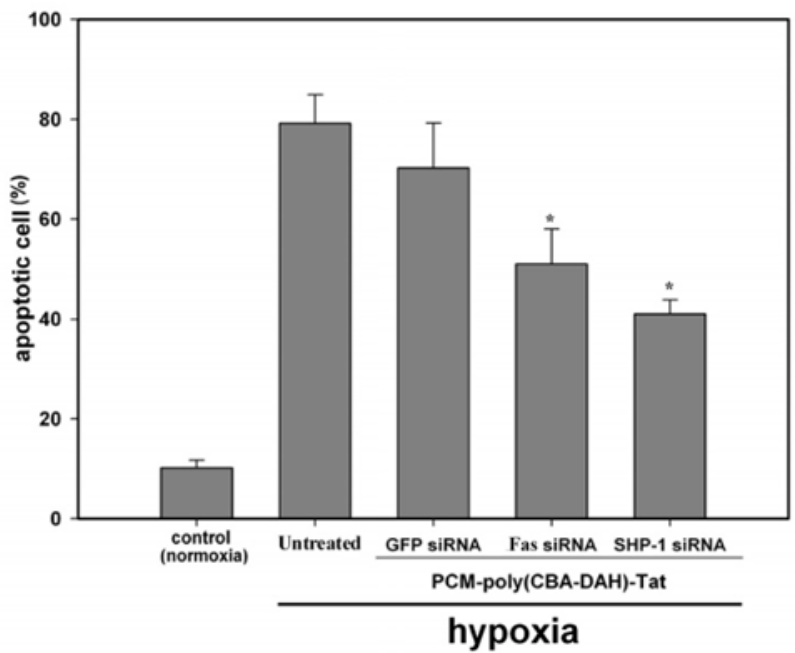

Figure 7.

FACS analysis for Annexin V-FITC and PI staining. (A) Representative histograms of normoxia (left) or hypoxia control (right). (B) Flow cytometry of apoptotic H9C2 cells transfected by siRNA polyplexes under hypoxic conditions. (C) Bar graph represents the mean percentages of apoptosis (FITC positive cells) in H9C2 cells under hypoxic conditions. ${ }^{*} \mathrm{p}<0.05$ versus all other groups under hypoxic conditions. 


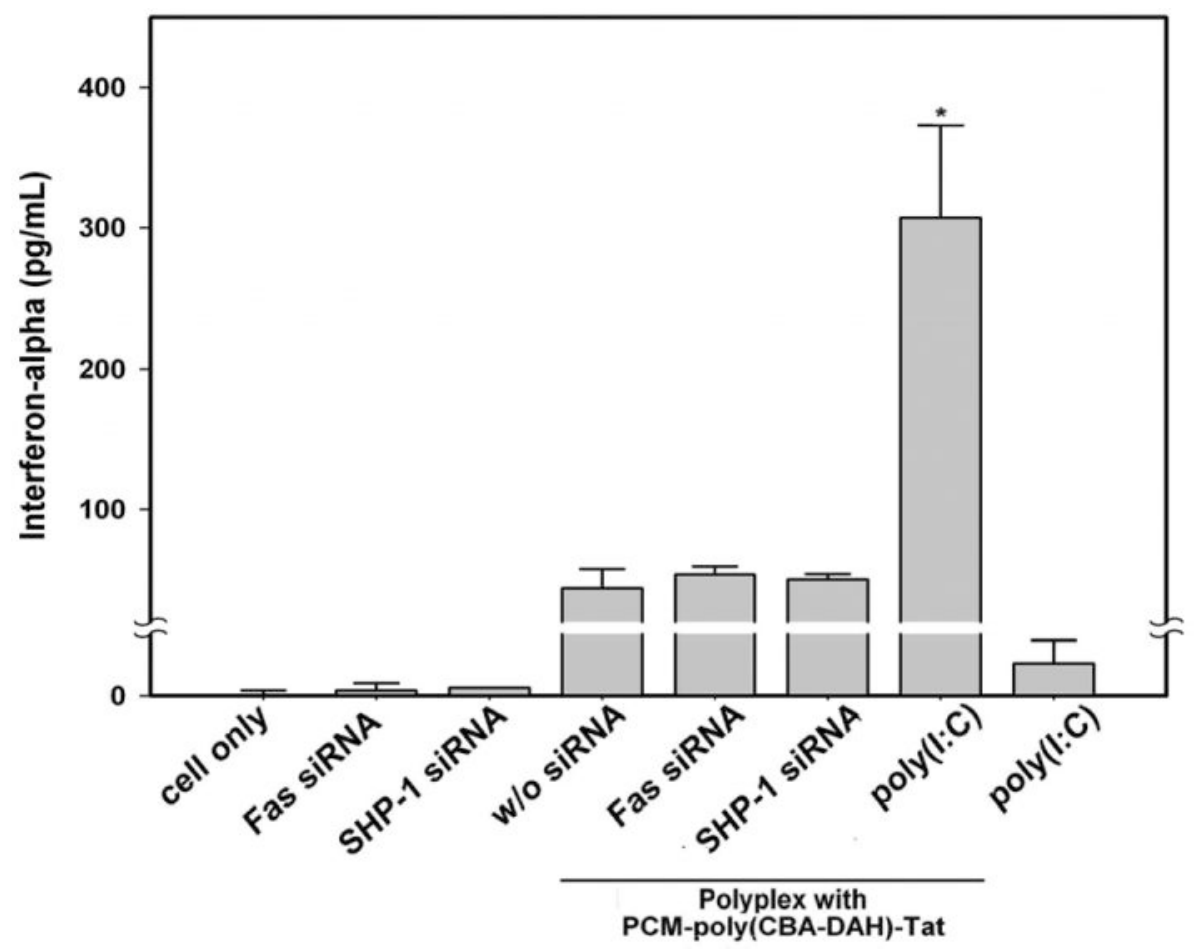

Figure 8.

Interferon-alpha response induced by SHP-1 siRNA polyplex transfection in PBMCs. The release of IFN- $\alpha$ was determined after $24 \mathrm{~h}$ of stimulation with treatment. ${ }^{*} \mathrm{p}<0.01$ for poly(I:C) with the polyplex system versus all other groups 
